EPJ Web of Conferences 45, 01111 (2013)

DOI: $10.1051 /$ epjconf/20134501111

(C) Owned by the authors, published by EDP Sciences, 2013

\title{
Evaluation of material properties determining the moisture transfer
}

\author{
M. Vestfálova ${ }^{1}$ \\ ${ }^{1}$ KEZ, TU Liberec, Studentská 2, 46117 Liberec 1, Czech Republic
}

\begin{abstract}
Due to solution the problems of moisture transfer is necessary to deal with two mechanisms of transfer: the molecular mass transfer and mass transfer by convection. Transfer driving force is the difference of concentrations of moisture, respectively the difference of partial vapour pressure. For molecular transfer is deciding value the coefficient of diffusivity, i.e. the property of the material. For mass transfer by convection is deciding the convection mass transfer coefficient, which depends on many parameters, but for one particular arrangement of the experiment will be influenced primarily velocity of the flow. Experimentally detectable is the overall moisture transfer caused by both mechanisms, i.e. the overall moisture transfer coefficient. Our goal was to attempt to evaluate the value of coefficient of diffusivity of some materials from the set of measured date. The date was obtained in different modes on different samples of materials. The next goal was to evaluate the dependence of the convection mass transfer coefficient on the speed of flow for the experiment alignment.
\end{abstract}

\section{Introduction}

The necessity to solute the problem of moisture transfer ensues on the Department of Power Engineering Equipment of Technical University of Liberec in connection on the solution of the project TA01020313. Its part was just the measurement of the amount of the transferred moisture of various materials. The experimental equipment was designed by Dančová et al. [1]. As the results of the measurement she obtained the mass flow of the vapour through various materials. For practise use of the results was necessary to evaluate "property" of the materials, best the coefficient of diffusivity.

\section{Description of the experiment}

In experimental measurements on the Department of Power Engineering Equipment of Technical University of Liberec [1] the moist air was flowing on both sides of the researched sample of material of rectangular shape. The airflow had the same temperature and pressure on either side of the sample. The air flow had lower relative humidity on the one hand of the material (we marked it "dry" air) and higher relative humidity beyond the material (we marked it "moist" air). The moister was transferred during the flow of air along the plate from the "moist" air to the "dry" air [2] and therefore the relative humidity of the air was changed on the both sides. The change of the relative humidity between input and output of both airflow was evaluated during the experiment. Experiment was conducted in two different modes of relative humidity of the "moist" air and in ten different modes of volume flow.

\subsection{Measured values}

During the experiment there was measured these values:

1. relative humidity of the ,dry“ air on the input (keeping in range $4.7-7.4 \%$ ),

2. relative humidity of the ,dry“ air on the output,

3. relative humidity of the ,moist" air on the input (first mode: $65-81 \%$, second mode: $40-70 \%$ ),

4. relative humidity of the ,moist" air on the output,

5. temperatures of "dry" and "moist" air on the input and on the output $\left(20-21{ }^{\circ} \mathrm{C}\right.$, isothermal process),

6. volume flow of the air through the exchanger (200 - 2000 1/hour., it is corresponding with speed of flow $0.26-2.6 \mathrm{~m} / \mathrm{s}$, ten modes),

7. pressure of "dry" and "moist" air on the input and on the output (barometric pressure just about $970 \mathrm{hPa}$ ).

\subsection{Experimental samples}

Ten different samples were measured:

1. $\quad$ sample $\mathrm{S} 1$ : material "S", $2.6 \mathrm{~g} / \mathrm{m}^{2}$, 
2. sample S2: material "S", $4.6 \mathrm{~g} / \mathrm{m}^{2}$,

3. sample $\mathrm{S} 3$ : material "S", $10.1 \mathrm{~g} / \mathrm{m}^{2}$,

4. sample S4: material "S", $11.7 \mathrm{~g} / \mathrm{m}^{2}$,

5. sample P1: material "PO", $16 \mathrm{~g} / \mathrm{m}^{2}$,

6. sample P2: material "PO", $21 \mathrm{~g} / \mathrm{m}^{2}$,

7. sample P3: material "PO", $27 \mathrm{~g} / \mathrm{m}^{2}$,

8. sample HO,

9. sample PA,

10. sample FP: filter paper.

\section{Evaluation of experiments}

\subsection{Calculation of the overall moisture transfer coefficient}

From the measured values it is possible to calculate the amount of the vapour

$$
\dot{m}_{\mathrm{V}}=\dot{V} \rho_{\mathrm{DA}}\left(x_{\mathrm{OUT}}-x_{\mathrm{IN}}\right),
$$

where

- $\dot{m}_{\mathrm{V}}$ - mass flow of the vapour, $\mathrm{kg}_{\mathrm{V}} \mathrm{s}^{-1}$;

- $\quad V$ - volume flow, $\mathrm{m}^{3} \mathrm{~s}^{-1}$;

- $\rho_{\mathrm{DA}}$ - partial density of the dry air, $\mathrm{kg} \mathrm{m}^{-3}$;

- $x$ - specific moister of the moist air, $\mathrm{kg}_{\mathrm{V}} \mathrm{kg}_{\mathrm{DA}}^{-3}$;

which transferred during the flow from the one side of plate to the other. For the known size of the area $A\left[\mathrm{~m}^{2}\right]$ of the sample it is possible to calculate the moister (vapour) transfer rate related to a unit cross section area, it means the vapour (moister) flux crossing the wall of the sample

$$
j_{\mathrm{V}}=\frac{\dot{m}_{\mathrm{V}}}{A}
$$

The same value it is possible to evaluate through the overall moisture (vapour) transfer coefficient as

$$
j_{\mathrm{V}}=k_{\mathrm{V}}\left(p_{\mathrm{VDA}}-p_{\mathrm{VMA}}\right),
$$

where

- $j_{\mathrm{V}}$ - vapour (moister) flax, $\mathrm{kg}_{\mathrm{V}} \mathrm{s}^{-1} \mathrm{~m}^{-2}$;

- $k_{\mathrm{V}}$ - overall moisture (vapour) transfer coefficient for the plane wall [3], $\mathrm{sm}^{-1}$,

$$
\frac{1}{k_{\mathrm{V}}}=\frac{1}{\beta_{\mathrm{DA}}}+\frac{t_{\mathrm{h}}}{D_{\mathrm{P}}}+\frac{1}{\beta_{\mathrm{MA}}} ;
$$

- $p_{\mathrm{VDA}}$, or $p_{\mathrm{VMA}}$ - partial pressures of the vapour in the "dry" air, or in the "moister " air, $\mathrm{Pa}$;

- $t_{\mathrm{h}}$ - thickness of the wall, $\mathrm{m}$;

- $\beta$ - convection moisture (vapour) coefficient from the flowing air to the wall, $\mathrm{s} \mathrm{m}^{-1}$;

- $D_{\mathrm{p}}$ - coefficient of diffusivity of the moister (vapour) regarding to the partial pressures, s.

Calculated values of the overall moisture (vapour) transfer coefficient according to the flow velocity for all sample you can see in figure 1 . When we compared the results, we can see that overall moisture (vapour) transfer coefficient:

1. in some cases it depends on the speed of the flow (S1, S2, S3, S4 a FP), in other cases it is almost independent on the speed of the flow (P1, P2, P3, HO, PA)

2. has the significant difference in values.

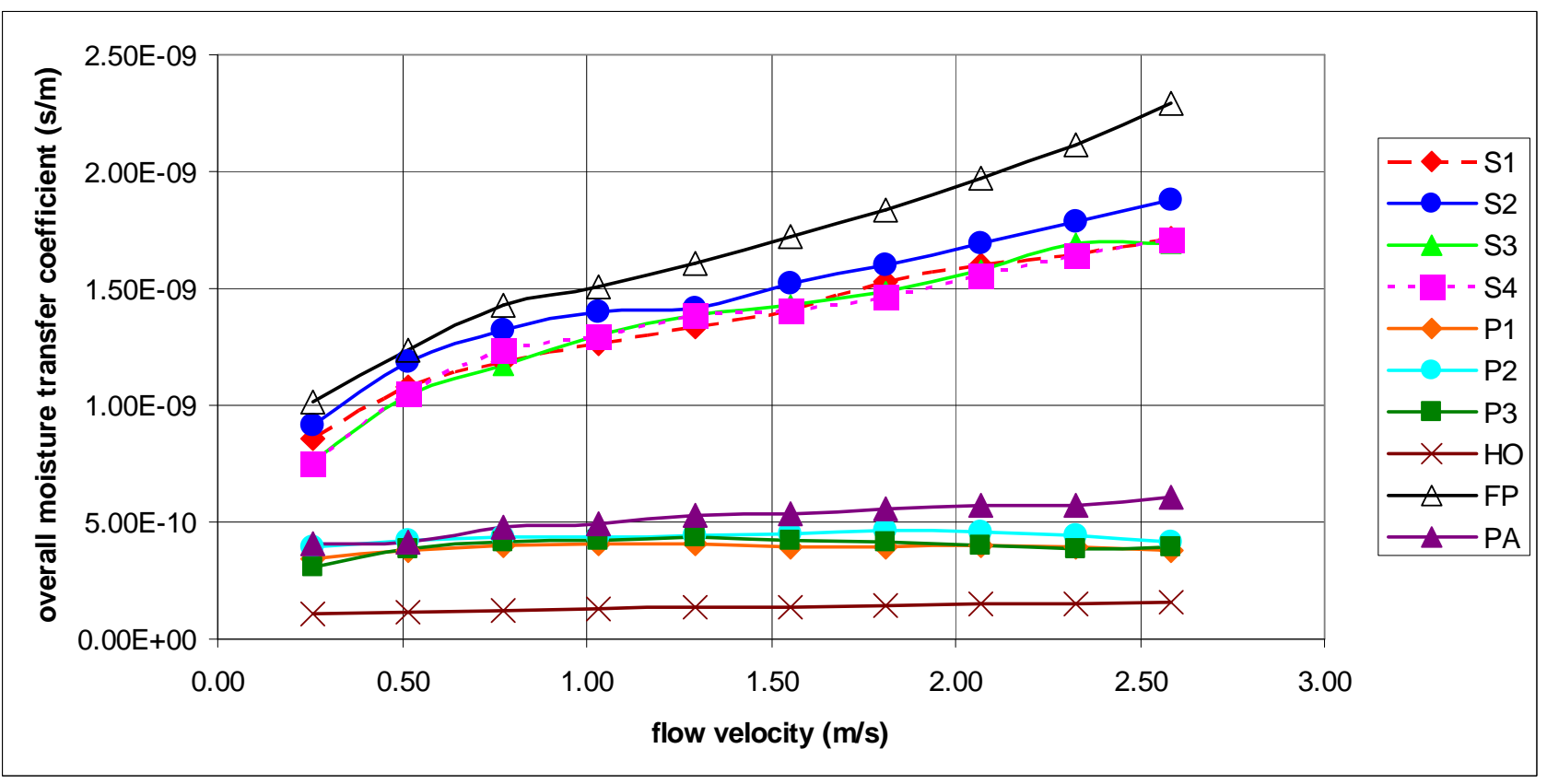

Fig. 1. The overall moisture transfer coefficient. 
We will assume that:

1. coefficient of diffusivity $D_{\mathrm{P}}$ (as the property of the material) is independent on the speed of the flow,

2. convection moisture (vapour) coefficient $\beta$ depends on the speed of the flow,

3. convection moisture (vapour) coefficient $\beta$ is independent of the material of the sample, it means $\beta_{\mathrm{DA}}$ will be equal $\beta_{\mathrm{DA}}$ and moreover it is the same in all cases,

we conclude that:

1. samples with the higher value of overall moisture (vapour) transfer coefficient $\mathrm{k}_{\mathrm{V}}$ have the higher value of the coefficient of diffusivity $D_{\mathrm{P}}(\mathrm{S} 1, \mathrm{~S} 2, \mathrm{~S} 3, \mathrm{~S} 4$ a FP),

2 . in the case of high value of the coefficient of diffusivity $D_{\mathrm{P}}$ is the term with the coefficient of diffusivity $\left(t_{\mathrm{h}} / D_{\mathrm{P}}\right)$ in equation for calculating of overall moisture (vapour) transfer coefficient $\mathrm{k}_{\mathrm{V}}$ (4) negligible to the term with convection moisture (vapour) coefficient $(1 / \beta)-$ in extreme cases will be the overall moisture (vapour) transfer coefficient given only the convection moisture (vapour) coefficient from the flowing air to the wall $\left(k_{\mathrm{V}}=\beta / 2\right)$,

3. vice versa, in the case of low value of the coefficient of diffusivity $D_{\mathrm{P}}$ is the term with convection moisture (vapour) coefficient $(1 / \beta)$ in equation for calculating of overall moisture (vapour) transfer coefficient $k_{\mathrm{V}}$ (4) negligible to the term with the coefficient of diffusivity $\left(t_{\mathrm{h}} / D_{\mathrm{P}}\right)(\mathrm{P} 1, \mathrm{P} 2, \mathrm{P} 3, \mathrm{HO}, \mathrm{PA})-$ in extreme cases will be the overall moisture (vapour) transfer coefficient given only the coefficient of diffusivity $\left(k_{\mathrm{V}}=D / t_{\mathrm{h}}\right)$ and it will be independent on the speed of the flow.

We can assume that the coefficient of diffusivity will be approximately equal to $D_{\mathrm{P}} \approx k_{\mathrm{V}} t_{\mathrm{h}}$ for the samples $\mathrm{P} 1$, P2, P3, HO.

\subsection{Calculation of the convection moisture (vapour) coefficient $\beta$}

The highest measured value of the overall moisture (vapour) transfer coefficient $k_{\mathrm{V}}$ has the filter paper. If we neglect in this case influence of the coefficient of diffusivity $D_{\mathrm{P}}$ on the overall moisture (vapour) transfer coefficient $k_{\mathrm{V}}$ (viz. the last paragraph) we can to obtain convection moisture (vapour) coefficient as $\beta=2 k_{\mathrm{V}}$ ( figure 2) for our arrangement of the experiment from the dates measured on this sample.

\subsection{Calculation of the coefficient of diffusivity for materials}

Assuming convection moisture (vapour) coefficient $\beta$ independent on the material of the sample we can calculate the coefficient of diffusivity $D_{\mathrm{P}}$ for each material (it will be independent on the speed of the flow) from the known dependence convection moisture (vapour) coefficient $\beta$ on the speed of the flow (figure 2)

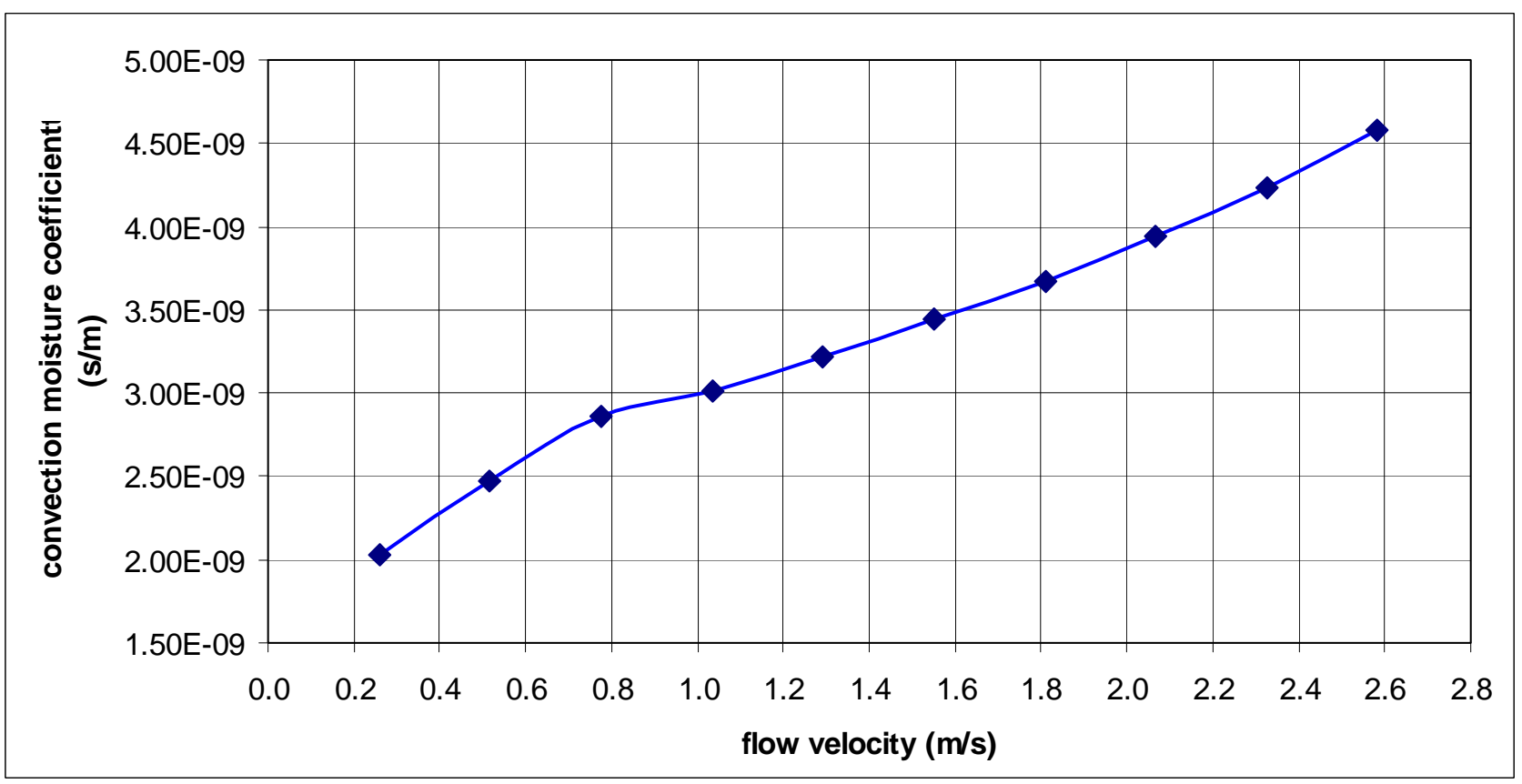

Fig. 2. The convection moisture coefficient. 


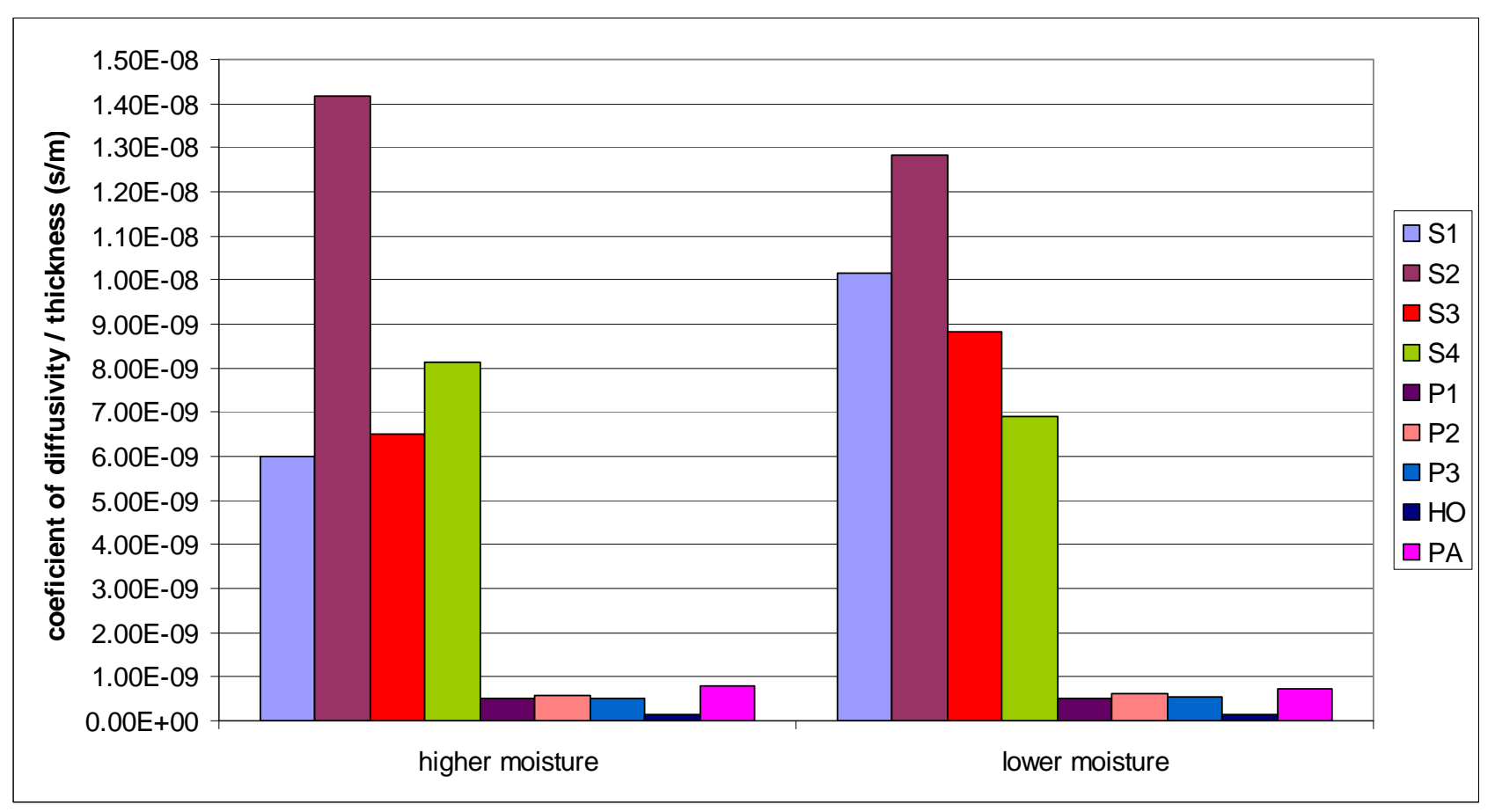

Fig. 3. The coefficient of diffusivity on different samples of materials for two modes of experiments.

$$
D_{\mathrm{P}}=\frac{t_{\mathrm{h}}}{\frac{1}{k_{\mathrm{V}}}+\frac{2}{\beta}} \text {. }
$$

The coefficient of diffusivity $D_{\mathrm{P}}$ for each measured material relative to their thickness $t_{\mathrm{h}}$ we can see in figure 3 .

\section{Conclusions}

- for the low values of overall moisture (vapour) transfer coefficient $\mathrm{k}_{\mathrm{V}}$ (samples $\mathrm{HO}, \mathrm{PA}, \mathrm{P} 1, \mathrm{P} 2$ and P3) are the values of coefficient of diffusivity identical for both modes of testing (for lower and higher value relative humidity of the inlet airflow of "moist" air),

- for the high values of overall moisture (vapour) transfer coefficient $k_{\mathrm{V}}$ (samples S1, S2, S3 and S4) are the values of coefficient of diffusivity different for both modes of testing (for lower and higher value relative humidity of the inlet airflow of "moist" air). For these materials are the values of the evaluated coefficients (coefficient of diffusivity $D_{\mathrm{P}}$, overall moisture (vapour) transfer coefficient $k_{\mathrm{V}}$, convection moisture (vapour) coefficient $\beta$ ) of the same magnitude and so the inaccuracies of the measurements and of the evaluation strong interact. Beyond coefficient of diffusivity these materials and filter paper (which was used for evaluation of convection moisture (vapour) coefficient $\beta$ ) has the same magnitude and these our assumptions are not quite alright.
- the values of the coefficient of diffusivity calculated assuming above simplifications are indeed independent on the speed of flow,

- in the sample with the lowest measured values of overall moisture (vapour) transfer coefficient $k_{\mathrm{V}}$ (material HO) corresponds the calculated value of the coefficient of diffusivity $D_{\mathrm{P}} \approx k_{\mathrm{V}} t_{\mathrm{h}}$, which refers to clause three in the chapter 3.1.

\section{Acknowledgment}

Author gratefully acknowledges financial support by Czech Technological Agency under the project TACR TA01020313.

\section{References}

1. P. Dančová, Z.Trávníček, T.Vít Exp. Fluid. Mech., 133 - 143 (2012)

2. M. S. Nasif, G. L. Morrison, M. Behnia, J., J. Applied Membrane Science \& Technology, 2, 3146 (2005)

3. L. Z. Zhang, J. L. Niu, Journal of Heat Transfer, 124, 922 - 929 (2002) 